\title{
CLÍNICAS DO TRABALHO: CONCEPÇÃO HISTÓRICA E DESENVOLVIMENTO DE UMA PROPOSTA HETEROGÊNEA
}

\author{
Clínicas Del Trabajo: Concepción Histórica Y Desarrollo De Una Propuesta Heterogénea \\ Work Clinics: Historical Conception And Development Of A Heterogenic Proposal \\ Cliniques Du Travail: Conception Historique Et Developpement D’une Proposition \\ Héterogène
}

\begin{abstract}
Lucas Martins Soldera ${ }^{1}$
Doutor em Psicologia (área de Conhecimento: Psicologia e Sociedade) pelo Programa de Pós-graduação em Psicologia da Faculdade de Ciências e Letras (UNESP/Assis). Profes sor do Departamento de Psicologia - DPI (área: Psicologia do Trabalho) da Universidade Estadual de Maringá (UEM). Pesquisador vinculado aos grupos de pesquis - Figuras e modos de Subjetivação no Contemporâneo; e Psicologia e Trabalho: dimensões sociais e subjetividade - ambos reconhecidos e certificados pelo CNPq. Membro do Laboratório Interinstitucional de Subjetividade e Trabalho - LIST
\end{abstract}

\begin{abstract}
RESUMO
O objetivo desse artigo foi realizar um resgate histórico sobre a formação das Clínicas do Trabalho, a fim de compreender como essa proposta se desenvolveu e se inseriu no território nacional. Para isso, foi utilizado um estudo teórico embasado na leitura, na pesquisa e na análise textual e conceitual do tema em obras referências para área. Foi empregado uma proposta internacional, denominada SIOP (Society for Industrial and Organizational Psychology) para, em seguida, definir a proposta da POT (Psicologia Organizacional e do Trabalho) no Brasil. Dentro da POT são encontrados três eixos temáticos sobre os quais ela foi construída: comportamento, subjetividade e clínico. É neste último eixo, o clínico, recentemente denominado de Clínicas do Trabalho que é encontrada a possibilidade de trabalhar com o caráter multi e interdisciplinar. Dessa forma, pretendeu -se contribuir com a expansão dos conhecimentos teóricos e metodológicos sobre as Clínicas do Trabalho e no entendimento de como essa proposta encontrou um contexto preparado para sua expansão, desenvolvimento e consolidação no Brasil. Assim, foi elaborada uma organização teórica da história dessa proposta, o que, por sua vez, possibilita a catalisação na produção de conhecimentos sobre a área. Pretendeu-se contribuir, ainda, para o desenvolvimento da atuação do profissional em psicologia do trabalho.
\end{abstract}

Palavras-chaves: Psicologia do Trabalho; Clínicas do Trabalho; Psicologia Organizacional do Trabalho.

\begin{abstract}
The objective of this article was to carry out a historical review on the formation of Work Clinics aiming at understanding how this proposal has developed, as well as has been inserted in the national territory. For this, it was used a theoretical study whilst the methodology was based on the bibliographical data, reading, research, and conceptual and textual analysis of theme. Initially, it was applied an international proposal called Society for Industrial and Organizational Psychology (SIOP) for then, afterwards, define the proposal of Work Organizational Psychology (WOP) in Brazil. Within WOP there are three thematic axes on which it was built: behavior,
\end{abstract}

${ }^{1}$ E-mail: solderamartins @ yahoo.com.br 
subjectivity and clinic. On this last axis, the clinic, recently named Work Clinics it was found the possibility of working with the multi and interdisciplinary character. This way it was intended to contribute with the expansion of methodological and theoretical knowledge on Work Clinics, and in understanding how this proposal found a context, prepare for its expansion and consolidation in Brazil. Thus, a theoretical organization of the history of this proposal was performed, which for its turn, made the speeding up of knowledge production on the area possible, contributing for the growth of Work Psychology professional's action.

Keywords: Work Psychology; Work Clinics; Work Organization Psychology.

\section{RÉSUMÉ}

Le but de cet article a été mené un répertoire historique des formations des Cliniques du Travail, à fin de comprendre comment cette proposition s'est développée et s'est insérée dans le territoire national. Pour ce faire, une étude théorique a été utilisée, alors que la méthodologie s'est basée sur la recherche bibliographique, la lecture, la recherche et l'analyse textuelle et conceptuelle de la thématique. Premièrement, une proposition internationale, nommée SIOP (Society for Industrial and Organizational Psychology), a été employée, pour, ensuite, définir la proposition de la Psychologie Organis ationnelle et du Travail (nommée POT, en Portugais) au Brésil. Dans la POT existent trois axes thématiques sur lesquels elle a été construite: comportement, subjectivité et clinique. C'est dans ce dernier axe, le clinique, récemment nommé Cliniques du Travail, que l'on trouve la possibilité de travailler avec le caractère multi et interdisciplinaire. De cette manière, on a cherché à contribuer avec l'expansion des connaissances théoriques et méthodologiques à propos des Cliniques du Travail et avec la compréhension de comment cette proposition a trouvé un contexte préparé pour son expansion, développement et consolidation au Brésil. Ainsi, une organisation théorique de l'histoire de cette proposition a été faite, ce que, par conséquent, permet le déclenchement de la production de connaissances dans le domaine. On a cherché à contribuer, en plus, à la croissance de l'action du professionnelde la psychologie du travail.

Mots-clés: Psychologie du Travail; Cliniques du Travail; Psychologie Organisationnelle et du Travail (POT).

\section{RESUMEN}

El objetivo de ese artículo fue realizar un rescate histórico sobre la formación de las Clínicas del Trabajo, a fin de comprender cómo es a propuesta se desarrolló y se introdujo en territorio nacional. Para eso, se utilizó un estudio teórico, y la metodología se basó en el levantamiento bibliográfico, en la lectura, en la investigación y en el análisis textual y conceptual del tema. Inicialmente, se empleó una propuesta internacional, denominada Society for Industrial and Organizational Psychology (SIOP) para, después, definir la propuesta de la Psicología Organizacional y del Trabajo (POT) en Brasil. Dentro de la POT se encontró tres ejes temáticos sobre los cuales ella se construyó: comportamiento, subjetividad y clínico. Es en este último eje, el clínico, recientemente denominado de Clínicas del Trabajo que es encontrada la posibilidad de trabajar con el carácter multi e interdisciplinar. De esa forma, se pretendió contribuir con la expansión de los conocimientos teóricos y metodológicos acerca de las Clínicas del Trabajo y en el entendimiento de cómo esa propuesta encontró un contexto preparado para su expansión, desarrollo y consolidación en Brasil. Así, se elaboró una organización teórica de la historia de esa propuesta, lo que, por su vez, posibilita acelerar la producción de conocimientos sobre el área y contribuir para el crecimiento de la actuación del profesional en Psicología del Trabajo.

Palabras Clave: Psicología del Trabajo; Clínicas del Trabajo; POT

\section{INTRODUÇÃO}

As Clínicas do Trabalho reúnem quatro abordagens diferentes epistemológica, ontológica e metodologicamente. São elas: Ergologia, Clínica da Atividade, Psicossociologia e Psicodinâmica do Trabalho. As quatro abordagens citadas são as mais indicadas por diversos autores, contudo devemos ressaltar os esforços de um grupo de pesquisadores brasileiros renomados que tem buscado uma proposta clínica pautada no paradigma estético e possui como principal referência a esquizoanálise de Deleuze e Guattari. Esses autores adotam o trabalho enquanto uma atividade ético-estético-político e reforçam a importância da diferença quando se 
aborda as relações de trabalho ${ }^{2}$.

Sabemos que existem diversos pesquisadores brasileiros que têm se empenhado para o desenvolvimento das clínicas no Brasil e que não foram citados nesse artigo. Não foi nossa intenção desmerecer seus trabalhos - muito pelo contrário - esperamos que esse artigo mobilize o leitor a buscar mais sobre o assunto deparando-se, assim, com o trabalho de outros autores. $\mathrm{O}$ que expusemos, aqui, foi uma das possibilidades de construção e desenvolvimento das Clínicas do Trabalho. Provavelmente, se adotássemos um outro referencial, essa construção também seria possível a partir de outros autores.

Após essa breve ressalva e, consequentemente, retomando nosso raciocínio, para tais clínicas não se visa formular uma disciplina lapidada no que se refere ao trabalho; ao invés disso, para ela a construção teórica deve acontecer concomitantemente e a partir da prática, para que, na discussão e no diálogo estabelecido entre elas - e suscitado por suas diferenças - cada uma se desenvolva ao seu modo.

De forma sucinta: a Ergologia tem em Yves Schwartz seu fundador, foi ele quem desenvolveu o método $d a$ autoconfrontação. Yves Clot é considerado o fundador Clínica da Atividade e do método da autoconfrontação cruzada. Existem muitos nomes importantes para a Psicossociologia, de forma simbólica, destacamos os nomes de Eugène Enriquez e Max Pagès como representantes. Enriquez esteve envolvido em todos momentos de transformações da Psicossociologia e Pagès foi quem primeiro empregou a denominação intervenção psicossociológica para um método específico. Christophe Dejours é considerado fundador. Clínica Psicodinâmica do Trabalho (CPDI ou Clínica do Trabalho) corresponde à intervenção específica dessa teoria e vem

2 Mais sobre a temática consultar: Amador, F.; Barros, M.E. B. e Fonseca, T.M.G. (2016). Clínicas sendo desenvolvida desde os anos 1980, com a obra A loucura no trabalho, desse próprio autor.

Todas elas conferem "novas" leituras e análises do contexto do trabalho, bem como abertura de "novas" perspectivas para a Psicologia do Trabalho em nosso país. Além do fato de considerarem, em primeiro lugar, as demandas do trabalhador, seja em relação à questão da saúde coletiva ou à da mobilização da subjetividade.

Encontramos no período após a Revolução Industrial o desenvolvimento das premissas capitalistas e das mudanças no mundo do trabalho, principalmente aquelas pautadas pela ideologia do taylorismo e, consequentemente, da exploração do trabalhador. Paulatinamente e paralelamente a esse domínio tecnicis ta do ambiente do trabalho, foram sendo desenvolvidas algumas formas para se trabalhar com uma vertente mais voltada às Ciências Humanas e Sociais. Essas vertentes do conhecimento possibilitaram ao profissional psicólogo, no decorrer da história, adotar uma conduta mais reflexiva sobre o papel do homem no processo produtivo e sobre o significado do trabalho para o sujeito e para o coletivo.

Para entendermos como as Clínicas do Trabalho se desenvolveram, construímos o caminho que essa proposta percorreu na história até chegar ao Brasil e se instaurar como uma possibilidade de avanço da Psicologia para o mundo do trabalho. Caminho esse que passa pelo desenvolvimento da proposta da Sociedade Brasileira de Psicologia, Organizações e Trabalho (SBPOT).

Portanto, nosso objetivo foi realizar um resgate histórico sobre a formação das Clínicas do Trabalho, a fim de compreender como essa proposta se desenvolveu e se inseriu no território nacional apresentando seu desenvolvimento o qual passou e ainda vem passando por diversas transformações.

Para tal, utilizamo-nos de um estudo teórico, embasado na leitura, na pesquisa e

do trabalho e paradigma estético. Porto Alegre: Editora UFRGS. 
na análise textual e conceitual do tema em obras referências para área. Essa proposta de construção histórica seguida de análise, segundo Severino (2007), pode funcionar como uma forma de sintetizar saberes e favorecer a produção de outros conhecimentos de uma área específica, contribuindo com o seu desenvolvimento.

Segue, então, o caminho pelo qual percorremos.

\section{Da Psicologia Organizacional e do Trabalho (POT) às Clínicas do Trabalho no Brasil}

Para o entendimento de como essa proposta clínica adentrou o Brasil, utilizamos uma proposta internacional, a SIOP (Society for Industrial and Organizational Psychology), para definição da SBPOT (Associação Brasileira de Psicologia Organizacional e do Trabalho) no Brasil. A partir da consolidação desse órgão, foi visualizado como a área evoluiu para um campo propício a receber $\mathrm{e}$ desenvolver a proposta das Clínicas do Trabalho em nosso país.

A SIOP é um órgão reconhecido pela APA (American Psychology Association) que, a partir de sua criação em 1996 -, ofereceu maior credibilidade à atuação do profissional nessa área, além de possibilitar sua expansão de atuação. Essa proposta embasou a regularização da atuação do profissional psicólogo no campo do trabalho em vários outros países.

Segundo a Siop, a prática do psicólogo no contexto do trabalho está dividida, hoje, em três vertentes: comportamento organizacional, gestão de recursos humanos e relações de trabalho (Gondim; Borges-Andrade; Bastos, 2010).

Essas três vertentes da SIOP delineiam a prática do psicólogo no campo do trabalho.

1. A primeira vertente (comportamento organizacional) fundamenta-se na análise do comportamento a partir de uma premissa experimental. Volta-se para uma intervenção focal, visando ao controle do indivíduo inserido no contexto organizacional. Estuda-se como o indivíduo, o grupo ou a própria estrutura organizacional interfere no comportamento dentro desse ambiente, identificando como sua configuração atinge o rendimento das pessoas, com o objetivo de promover o aumento da eficácia da produção. Aqui são trabalhados temas como desenho organizacional, segurança no trabalho, liderança, empreendedorismo, entre outros.

2. Já a segunda vertente (gestão de recursos humanos) objetiva alinhar as práticas e a política do gerenciamento de pessoas às estratégias organizacionais. Apesar de significar um grande avanço e conquista para a área de RH (Recursos Humanos) dentro das organizações, essa vertente ainda limita a atuação do psicólogo dentro da organização em algumas atividades técnicas, como recrutamento, seleção, treinamento e atividades relacionadas à administração de recursos humanos (avaliação de desempenho, coaching, desenvolvimento profissional, entre outros).

3. A terceira vertente (relações de trabalho) trabalha com questões envolvendo motivação, interrelacionamentos, socialização, comunicação, bem-estar e assédio, além de expandir a perspectiva de intervenção ou análise, dentro ou fora do ambiente de trabalho, visando promover uma interface com a sociedade.

É nessa terceira proposta que se insere uma nova possibilidade de atuação da 
Psicologia, baseada na Psicologia Social voltada para estudo de fenômenos como identidade, interação social, subjetividade, geralmente direcionada para públicos menos privilegiados e para a Saúde Coletiva, com vista à saúde do trabalhador e às consequências do trabalho ou da falta dele.

Apesar das várias possibilidades que o psicólogo tem para trabalhar, segundo a proposta da SIOP, já se tem estabelecido uma expansão e releitura dessas propostas. Considera-se que as novas formas de se pensar o mundo do trabalho são relevantes, além de corroborar na visualização do que se está construindo.

As novas possibilidades de trabalhar com a Psicologia dentro das organizações, opondo-se ao neopositivismo, tornaram o cenário mais diversificado. Entretanto, não é fácil escolher entre tanta diversidade. Bendassolli, Borges-Andrade e Malvezzi (2010) corroboram expondo que, no Brasil, essa diversidade corresponde ao amadurecimento da Psicologia do Trabalho, ao mesmo tempo que traz preocupações:

Isso porque tal cenário coloca sobre o pesquisador e profissional em questão a contínua necessidade de confrontar suas atividades com os referenciais que legitimam sua atuação. Por esse motivo, a reflexão crítica sobre as bases epistemológicas, ontológicas e metodológicas que orientam e fundamentam seu trabalho surge como condição essencial de sua competência profissional (Bendassolli, Borges-Andrade e Malvezzi, 2010, p.287).

Tal proposta possibilita a expansão do objeto de estudo, não ficando mais restrito à estrutura da organização e às funções, desde que os trabalhos tenham como preocupação principal a relação Homem/Trabalho. Ao assumir essas "orientações", o psicólogo passa a ocupar uma posição de promotor de saúde, fazendo com que a Psicologia do Trabalho conquiste mais um espaço dentro do mundo do trabalho. Vale ressaltar que esse espaço deve ser construído pelo profissional em questão, já que não está posto de forma sistematizada; ao contrário, ele é antes de tudo dinâmico e constitui uma conquista dos atores envolvidos no contexto do trabalho.

Nessa nova perspectiva em construção, o trabalho configura-se como um importante conferidor de identidade, da vida psíquica, social, cultural, política e econômica do indivíduo. Podemos, então, a partir do trabalho, segundo Enriquez (2000), constituir uma possibilidade de autonomia, ou seja, um sujeito "criador da história".

Não se busca apagar as diferenças entre as propostas, já que esse campo está em constante debate. Contudo, surge aqui, além da proposta de expansão desses conhecimentos, a expansão da atuação do profissional da área, que, ao mesmo tempo, rompe os "muros" das organizações e adentra seus níveis estratégicos.

Com o objetivo de contemplar essa expansão e a diversidade teórico-prática consequente, surge no Brasil a denominação Psicologia Organizacional e do Trabalho (POT), empregada desde o fim da década de 1990. Recentemente, essa proposta teve seu nome alterado para Psicologia, Organizações e Trabalho (mantendo a sigla POT). Existe, ainda, uma forte discussão dentro da Associação Nacional de Pesquisa e Pós-graduação em Psicologia (ANPEPP) em utilizar a denominação Psicologia do Trabalho e Organizacional (apesar de alterada a ordem a sigla POT se mantém), a fim de contemplar exatamente a diversidade que vem surgindo na área. Porém, é a partir de 2001, com a fundação de uma associação, visando fortalecer politicamente a POT no cenário nacional, que surge a SBPOT (Sociedade - ou Associação - Brasileira de Psicologia Organizacional e do Trabalho).

A associação se consolidou e se fez presente em congressos e em debates sobre questões políticas que envolviam o papel da 
Psicologia e da POT perante a sociedade, o que levou ao reconhecimento frente ao CFP (Conselho Federal de Psicologia). Fundase, mais adiante, a rPOT (revista Psicologia: Organizações e Trabalho). A divulgação de um periódico especializado na área possibilitou ainda mais a expansão da proposta.

A ideia da formação de uma associação é a de construir uma grande rede integrada de estudiosos e interessados, que até então mantinham sua produção em núcleos distintos e geograficamente espalhados pelo país, para que, assim, se possa avançar, cada vez mais, em projetos de cooperação em pesquisa, intercâmbio de conhecimentos, experiências e produção bibliográfica. Tal proposta só foi possível em decorrência do grande avanço da área, a partir das últimas décadas. Segundo dados encontrados no site da Associação Brasileira de Psicologia Organizacional e do Trabalho, ${ }^{3}$ atualmente a associação reúne 246 membros, entre pesquisadores, profissionais e estudantes.

Segundo Zanelli, Borges-Andrade e Bastos (2007, p. 489), esse movimento desencadeado e conduzido pela SBPOT pode "contribuir para o fortalecimento da identidade dos psicólogos brasileiros nesse segmento de atuação e resultar em maior integração, clareza de propósitos e segurança no exercício profissional”.

A expansão da área e a diversidade de atuações, muitas vezes, faz com que o profissional se perca em meio às possibilidades de orientação teórica e epistemológica de sua prática, ou mesmo não busque essas orientações, caindo no senso comum e na comodidade da aplicação da "técnica pela técnica" (Zanelli; BorgesAndrade e Bastos, 2007).

Esse tipo de conduta alheia dos profissionais levanta alguns pontos a serem considerados, como: quais as teorias vêm embasando a prática do profissional psicólogo no campo do trabalho? O que o profissional tem feito para a atualização de conhecimento em relação à sua área de atuação? Apesar das possibilidades de atuação que o termo POT traz para a área, ainda temos a preocupação sobre o que realmente está sendo feito na prática.

A orientação dessa proposta é de que, no contexto do trabalho, cabe ao psicólogo:

[...] compreender o comportamento das pessoas que trabalham, tanto em seus determinantes e suas consequências, como nas possibilidades de construção produtiva das ações de trabalho, com preservação máxima da natureza, da qualidade de vida e do bem-estar humano (Zanelli; Borges-Andrade e Bastos, 2007, p.483).

Essa orientação e a expansão da atuação do profissional geram "novas" possibilidades de análise e intervenção sobre o mundo do trabalho. Bendassolli, Borges-Andrade e Malvezzi (2010) relatam que dentro da POT são encontrados três eixos temáticos sobre os quais ela foi construída: comportamento, subjetividade e clínico.

1. O eixo comportamental é marcado, principalmente, pelo caráter experimental, no controle das variáveis e correlação de dados, a partir de uma análise behaviorista. "Há certa convergência nos métodos, especificamente no uso da estatística, com inspiração predominantemente correlacional, visando o diagnóstico e a gestão" (Bendassolli, BorgesAndrade e Malvezzi, 2010, p. 284).

2. O segundo eixo considera a subjetividade e o trabalho; começou a ganhar força no Brasil a partir de 1990 e refere-se ao indivíduo e ao seu comportamento em relação à sua cognição e afeto; o sujeito ocupa

\footnotetext{
${ }^{3}$ Disponível em: <http://sbpot.org.br $>$. Acesso em: maio 2016.
} 
lugar de ser pensante e responsável por suas ações, exposto, entretanto, às influências histórico-sociais.

No campo da POT, os estudos partindo do referencial pós-estruturalista sobre subjetividade e processos de subjetivação dedicam-se à exploração de amplo leque de temas, cuja síntese seria impossível de apresentar integralmente aqui. Contudo, além do que já foi dito, é possível pontuar alguns tópicos comuns de investigação, tais como a crítica a processos tradicionais de institucionalização do trabalho; a tentativa de empoderar indivíduos e grupos sociais em condições de fragilização no trabalho; a genealogia de formas de construção e disseminação de significados sobre o trabalho; o desenvolvimento de políticas públicas que levem em consideração fatores subjetivos; o estudo dos impactos subjetivos do desemprego, subemprego e de processos de reestruturação produtiva; a relação entre trabalho e questões de gênero (Bendassolli, Borges-Andrade e Malvezzi, 2010, p. 285).

As pesquisas visam a uma perspectiva crítica e são elaboradas nesse eixo em busca da intervenção e da transformação das condições de trabalho, atentando para a relação entre homem e trabalho.

3. Já o eixo clínico - que recentemente recebeu a denominação de Clínicas do Trabalho - considera que:

[...] mesmo sem focar a questão psicoterapêutica, partilham características do paradigma clínico, tais como o foco em metodologia qualitativa, o recurso à interpretação, a ênfase na profundidade da compreensão de casos específicos em detrimento de descrições ou descobertas de leis gerais (Bendassolli, Borges-Andrade e Malvezzi, 2010, p. 285).
Se no eixo da subjetividade valoriza-se o papel de um trabalhador ativo com poder de ação e se considera também as questões subjetivas, no eixo clínico as questões subjetivas aparecem com algo a mais, como uma forma de resistência (defesa) de um espaço psíquico muitas vezes esquecido ou deixado de lado pelas organizações capitalistas.

Aqui, encontramos uma discussão sobre as formas de construção do objeto de estudo. Para o eixo clínico deve-se possuir um esqueleto metodológico, a fim de nortear a conduta do pesquisadorinterventor no campo e garantir a cientificidade da proposta. Contudo, essas orientações não podem engessar a atuação do mesmo, deve-se dar espaços aos conhecimentos construídos na prática e as conscientizações e transformações mobilizadas pela intervenção, ou seja, os próprios grupos devem conduzir seu desenvolvimento. Dessa forma, o objeto de estudo não é dado pelo pesquisadorinterventor e sim construído pelos seus integrantes na própria prática.

Nesse eixo clínico, no bojo das discussões que envolvem sempre o caráter multi e interdisciplinar e a partir das possibilidades de reflexão, estudo e atuação, encontra-se - no Brasil, dentro da proposta da Psicologia Organizacional e do Trabalho (POT) - a possibilidade de se trabalhar com as Clínicas do Trabalho.

De fato, o mundo está em constante transformação, razão pela qual é necessário cada vez mais o desenvolvimento de uma complexa rede de conhecimento para apreendê-lo. Por sua vez, as Clínicas do Trabalho ganham destaque.

Frente ao desenvolvimento das clínicas destacamos alguns livros que caracterizam esse movimento de crescimento dessa proposta no Brasil: Métodos de pesquisa e intervenção em psicologia do trabalho: clínicas do trabalho (Bendassolli; Soboll, 2014); Clínicas do Trabalho: novas perspectivas para compreensão do trabalho na 
atualidade (Bendassolli; Soboll, 2011a) e cliniques du travail (Lhuillier, 2011a).

Métodos de pesquisa e intervenção em psicologia do trabalho: clínicas do trabalho, de 2014, é um livro organizado por Pedro F. Bendassolli e Lis A. Soboll e representa um amadurecimento, no Brasil, das teorias voltadas para o estudo das questões do trabalho, em especial para as Clínicas do Trabalho. Essa obra aborda as metodologias e os métodos das Clínicas do Trabalho, constituindo um guia para as pesquisas e intervenções, a fim de compreender os aspectos humanos e subjetivos relacionados ao trabalho.

A proposta dessa publicação é formalizar as práticas de atuação e os métodos, bem como discutir o desenvolvimento dos dispositivos utilizados para tal, já que a premissa está na produção de saber enraizada na prática de diferentes abordagens. Por isso, fica claro que a proximidade entre as teorias não significa fusão entre elas. A ideia está no reconhecimento da outra e no trabalho constante de diálogo e controvérsias.

Clínicas do Trabalho: novas perspectivas para compreensão do trabalho na atualidade, de 2011, constitui hoje uma das principais referências sobre o tema no Brasil. Pedro F. Bendassolli e Lis A. Soboll organizam, nessa obra, textos introdutórios relacionados a cada uma das abordagens que compõem as clínicas. O livro oferece um panorama dos fundamentos de tais abordagens, além das perspectivas francesas e brasileiras acerca dessa proposta. Para isso, os textos foram escritos por autores que são referências em suas respectivas áreas, na França ou no Brasil.

Além da apresentação das quatro teorias que compõem as Clínicas do Trabalho, a obra possibilita um diálogo entre as abordagens. A ideia foi expor os pontos de convergência e as limitações de cada uma, contemplando, sempre, a relação entre trabalho e subjetividade.

É possível verificar que a origem da proposta clínica no contexto do trabalho está ligada, diretamente, aos estudos sobre
Saúde Mental e Psiquiatria. Posteriormente, o caráter clínico se pautou na transformação efetiva do trabalho diante de situações de sofrimento e adoecimento. Na obra, ainda se faz menção às quatro abordagens clínicas, a partir das referências francesas, oferecendo visões particulares sobre o trabalho humano dentro das organizações. $O$ final do trabalho retrata, a partir das referências brasileiras, algumas perspectivas e possibilidades que essas abordagens podem suscitar em território nacional.

Apesar de o livro Cliniques $d u$ travail, publicado a França por Dominique Lhuillier, em 2011, ainda não possuir tradução para o português, trata-se de uma das referências da área para quem se interessa por tal proposta clínica.

Nessa obra, a autora esclarece que a proposta das Clínicas do Trabalho é a de compreender, analisar e transformar as situações de trabalho que causam males aos trabalhadores. A fim de conferir esclarecimento ao trabalhador, a autora traz uma apresentação das principa is orientações que tornam possível usar várias teorias e metodologias.

O conceito de trabalho é entendido como possuidor de funções psicológicas e sociais, por isso se torna parte constituinte do sujeito. Dessa forma, a investigação proposta pelas clínicas visa entender 0 sofrimento, as manifestações e processos de resistência advindos desse trabalho. Para tal, é imprescindível a implicação dos sujeitos nesse processo.

A autora defende um espaço dinâmico para construção das análises em Clínicas do Trabalho. Um espaço onde são construídos laços sociais e intersubjetivos, mobilizados pela confrontação com as realidades materiais e simbólicas.

Também existem artigos sendo publicados por autores brasileiros e em parcerias com autores franceses que demonstram o interesse pela área e o crescimento da mesma. Cada abordagem teórica encontrou sua forma de desenvolvimento em nosso território e hoje, 
cada vez mais, todas têm se apoiado na heterogeneidade dos diálogos para continuar essa expansão.

\section{O desenvolvimento das Clínicas do Trabalho}

Expusemos, nesse momento, como a proposta das Clínicas do Trabalho veio sendo pensada no decorrer da história. Tanto na França (seu berço) como no Brasil, a sua história não se inicia a partir da intitulação Clínicas do Trabalho, visto que ela veio se construindo a partir de um processo dinâmico no decorrer dos anos.

Vários esforços de pesquisadores e profissionais têm sido ressaltados no intuito de conseguir a sustentação das práticas dessa proposta, a fim de analisar, compreender e transmitir as experiências desenvolvidas. Percebe-se, então, a necessidade de pensar o trabalho e sua descaracterização diante das novas formas de gestão e organização.

No campo da Psicologia Organizacional e do Trabalho (POT), as clínicas do trabalho contrapõem o modelo dominante da psicologia organizacional de ênfase congniti vocomportamental, tendo em vista que apresentam finalidades diferenciadas em relação aos objetivos organizacionais e aos objetivos dos trabalhadores (Bendassolli; Soboll, 2011b, p. 16).

A Psicologia Organizacional e a Psicologia do Trabalho estão agrupadas dentro da mesma perspectiva da POT. Algumas áreas se pautam mais pelo caráter tecnicista, enquanto outras contrapõem esse modelo dominante, como é o caso das Clínicas do Trabalho.

Entre seus traços fundamentais, as clínicas do trabalho defendem a centralidade psíquica e social do trabalho, entendido como uma atividade material e simbólica constitutiva do laço social e da vida subjetiva. Elas atribuem grande importância às situações concretas de trabalho, valorizando um questionamento sobre as demandas colocadas pelo mundo do trabalho aos psicólogos e também sobre o uso dos dispositivos propostos quando da análise, pesquisa e interve nção naquelas situações (Bendassolli; Soboll, 2011b, p. 17).

Esse, por sua vez, é um movimento recente no Brasil e demonstra uma preocupação das pesquisas acadêmicas com a crise contemporânea do trabalho, uma vez que exige um engajamento profissional de todos que desejam mudar - na prática - as situações de trabalho.

Segundo Lima (2011), o embrião desse movimento se deu na França com alguns estudos de Lahy e Pacaud, na época da Primeira Grande Guerra Mundial, nos quais os referidos autores começaram a analisar as situações de trabalho mais especificamente. Para tanto, tornou-se necessária a aprendizagem de alguns ofícios por parte dos autores/pesquisadores. Isso leva à constatação de que o psicólogo não deve se contentar somente com a descrição do cargo, mas deve, também, adentrar o campo da prática. Entretanto, tais estudos focavam-se na aptidão pessoal de cada trabalhador, abstraindo a importância do seu caráter social. Isso fez com que Faverage estabelecesse uma crítica a essa concepção nos anos 1950; a partir de então, ele foca seus estudos em uma análise ampliada e participativa do psicólogo no ambiente de trabalho.

No campo da Saúde Mental, mais especificamente na Psiquiatria, autores como Sivadon e Le Guillant são considerados precursores dos estudos em Psicopatologia do Trabalho. Esses autores começaram abrindo o caminho para uma clínica (social) das situações de trabalho e, posteriormente, Veil passou a entender a vida mental e seus possíveis distúrbios 
produzidos na relação do indivíduo com sua atividade (Lima, 2011).

Sivadon, em 1957, publicou um artigo intitulado Psychiatrie du travail, no qual aborda problemas de adaptação individual no trabalho centrados na fragilidade dos próprios trabalhadores, introduzindo a expressão "neurose do trabalho" como resultado do desequilíbrio da pessoa no que tange à adaptação ao ambiente de trabalho. Veil, em 1964, publica um livro nomeado Higiène mentale du travail, no qual propõe uma ampliação da proposta anterior (de Sivadon), unindo, à análise individual e psicológica, aspectos da organização do trabalho, considerando dois aspectos: o trabalho como fonte de sofrimento e como atividade criativa por meio da sublimação. Contudo, é com Le Guillant, em um livro publicado em 1984, ${ }^{4}$ Quelle psychiatrie pour notre temps, que percebemos o abrir das portas para a criação de uma clínica social relacionada diretamente ao trabalho. Em sua publicação, o autor aborda a indivisível união entre o sujeito e seu meio, partindo da análise concreta das situações vivenciadas pelo trabalhador, pois nelas estão as patologias decorrentes (Bendassolli; Soboll, 2011a).

Tosquelles foi outro autor que também contribuiu para a futura perspectiva das Clínicas do Trabalho, colaborando com o desenvolvimento das terapêuticas do trabalho e da Saúde Mental no Trabalho. Ele averiguava o potencial terapêutico da atividade laboral por meio de uma ação transformadora não só do indivíduo, como do próprio psicólogo. $\mathrm{O}$ autor aborda $\mathrm{o}$ lugar do trabalho como via terapêutica e as atividades de trabalho em si como possibilidades de cura (Bendassolli; Soboll, 2011a).

A ideia de Tosquelles foi fazer com que pacientes e profissionais (do hospital onde desenvolveu seus estudos) trabalhassem para cuidar da instituição e que esta, por sua vez, reconhecesse esses pacientes como seres humanos responsáveis pelas suas atividades, ou seja, pela construção de um mundo onde tais pacientes tenham liberdade de elaborar experiências do real.

Já em 1980, Dejours publica o livro - traduzido no Brasil em 1992 - A Loucura do Trabalho, marcando o início da consolidação do que seria essa proposta no futuro. Devemos ressaltar que o movimento das Clínicas do Trabalho vem sendo construído desde tais datas; contudo, essa proposta receberá sua nomeação somente mais tarde.

Poder-se-ia pensar, ainda, a partir de sua constituição histórica, na possibilidade de nomeá-la como Clínica do Trabalhador, mas a proposta é mais abrangente, não se restringindo às pessoas que desempenham ou não uma atividade produtiva (a partir de uma relação contratual). $\mathrm{O}$ conceito de Clínicas do Trabalho está pautado na relação homem/trabalho e na transformação dessa relação e do meio em que está, independentemente de onde esteja. Assim, podemos abordar questões do trabalhador, do não trabalho, do ser humano em geral e, também, do mundo do trabalho como um todo.

Tem-se, então, a definição de Clínicas do Trabalho como:

[...] um conjunto de teorias que tem como foco de estudo a relação entre trabalho e subjetividade. Apresentando uma diversidade epistemológica, teórica e metodológica, o objeto comum dessas teorias é a situação do trabalho, que, em síntese, compreende a relação entre o sujeito, de um lado, e o trabalho e o meio, de outro (Bendassolli; Soboll, 2011a, p. 3).

\footnotetext{
${ }^{4}$ Esta publicação é uma reedição constituída por uma compilação de textos já publicados nos anos 1960, independentes entre si.
} 
O nome Clínicas do Trabalho é uma alusão de que é possível trabalhar com a articulação entre o mundo social e o mundo psíquico. Assim, a realidade vivenciada pelo sujeito se torna o foco de pesquisa e intervenção desta proposta, mantendo-se próxima da questão dos sofrimentos, aqui encontrada nas experiências objetivas e subjetivas do indivíduo nas situações de trabalho.

Para entender melhor a denominação dessa proposta, volta-se às primeiras referências ao termo clínica. Segundo Sévigny (2001), a palavra clínica está etimologicamente ligada ao ato de observar diretamente junto ao leito do paciente, ou seja, estar perto de e face a face com. Percebe, então, a relação da palavra com a atuação médica, embora não se refira à forma como é praticada atualmente. Refere-se, sobretudo, à postura do profissional médico (no início de seus trabalhos na história) ao se debruçar sobre os problemas do paciente, dispondo apenas de seus próprios recursos. Nesse sentido, quando é aplicado às Ciências Humanas, o termo clínica volta-se para uma prática centrada em casos individuais, problemáticos, que necessitam de solução.

A Psicologia Clínica foi bastante influenciada pela psicanálise (que também teve sua origem no modelo médico). Para buscar compreender o homem como um todo, essa Psicologia Clínica não visa apenas ao psicopatológico e não pode se restringir apenas às dimensões inconsciente, sexual e infantil. É nesse momento que ela:

[...] é necessariamente levada à interdisciplinaridade. É isso aliás o que faz, ao mesmo tempo, a riqueza e o desconforto dessa orientação, orientação que criou um quadro necessariamente móbil para responder às exigências das práticas clínicas. Essa não se confunde com a prática analítica, que se apoia sobre um dispositivo particular, notadamente sobre o trabalho de transferência e a suspensão da realidade externa para criar condições para a emergência da vida fantasmática. Quanto às práticas clínicas, elas são diferentes, mas sempre inscritas no contexto social (Lhuillier, 2011b, p.25).

Ainda pensando essa prática clínic a no âmbito social, Sévigny (2001, p.15) complementa:

Contudo, aqui os "problemas" não recaem apenas sobre o indivíduo, como também grupos, organizações, instituições, situações sociais examinadas em suas especificidades (individualidades), não se tratando de curar, mas sim de mudar, prevenir ou melhorar uma dada situação em resposta a problemas.

A ideia da prática clínica levada ao campo social dá abertura para as pesquisas e possibilita trabalhar com o conceito de clínica, já que o mesmo não se refere exatamente ao caráter clínico praticado dentro do setting terapêutico que aborda questões das problemáticas individuais. Dessa forma, a abordagem clínica não se restringe a um conceito em Ciências Humanas, pois ela está voltada para a ação, fazendo parte do campo de intervenção, parte da realidade social. Nesse campo é impossível controlar a situação, diferentemente dos casos em abordagens experimentais. Logo, na abordagem clínica é necessária a constatação de uma espécie de impotência por parte do pesquisador em relação à sua ausência de controle sobre o objeto de estudo.

O clínico é levado a interagir com os atores (sujeitos) da situação, tornando-se um deles, constituindo-se parte do grupo. Além disso, não se deve desconsiderar nenhum tipo de conhecimento, seja ele de ordem prática ou teórica. Refere-se ao caráter clínico quando a intenção é deixar em evidência a relação entre o trabalho e os processos de subjetivação, "de forma que os 
conhecimentos produzidos nesta perspectiva oportunizam conscientização relativa às vivências nas relações de trabalho, visando transformação da realidade" (Bendassolli; Soboll, 2011a, p.4).

Busca-se, então, sempre o aumento do poder de ação dos sujeitos a partir de metodologias principalmente qualitativas, uma vez que, na proposta das Clínicas do Trabalho, é relevante não apenas a manifestação do sofrimento, como também os esforços da vida no palco cotidiano, local onde o homem é constantemente colocado à prova. Essa realidade é construída pelas relações e práxis desses indivíduos, já que é onde estão as dinâmicas sociais essenciais à atividade produtiva, aspectos tão importantes quanto o patológico, a dimensão inconsciente, o sexual e o infantil, para a compreensão desse homem multideterminado. Assim:

Não se pode pensar a questão do sujeito sem inscrevê-lo numa dupla determinação: social e psíquica. Se o indivíduo é produto de uma história, esta condensa de um lado, o conjunto dos fatores sócio-históricos que intervêm no processo de socialização $\mathrm{e}$, de outro, o conjunto de fatores intrapsíquicos que determinam a sua personalidade (Gaulejac, 2001, p.41).

Nesse processo complexo de possibilidades, afirmamos que a proposta das Clínicas do Trabalho tem seu foco, principalmente, nos processos emancipatórios do trabalhador em vez do desempenho produtivo.

Isso é plausível pela premissa metodológica que aponta para o papel do pesquisador em duas frentes: a) como "clínico social", que visa à transformação efetiva do trabalho, pautando-se pela diminuição do sofrimento humano e por melhoras nas condições de trabalho, e b) como "pesquisador-clínico", que visa ao questionamento constante do próprio conhecimento produzido (Bendassolli; Soboll, 2011a).

Devemos ressaltar os esforços anteriores de estudiosos e práticos do método da pesquisa-ação, que contribuíram para expansão da área, iniciados com os estudos norte-americanos de Psicologia Social, com Kurt Lewin. Nesse sentido, Thiollent (2011) relata que esse método tem valor porque estabelece discussão de propostas, exposição de conflitos dentro das organizações, que podem levar à resolução das questões. Seu compromisso é proporcionar investigação e levantamento de problemas, bem como suas particularidades.

A pesquisa-ação se torna, então, importante para as práticas das Clínicas do Trabalho, uma vez que estas propõem um envolvimento do psicólogo, atuando como ativo na transformação dos processos organizacionais, como visto anteriormente nos estudos que a influenciaram.

Para tanto, é imprescindível a conscientização e o empowerment desses sujeitos submetidos ao contexto do trabalho (dentro ou fora das organizações), estabelecendo um enfrentamento real do trabalho, no qual serão confrontados aspectos fantasiosos e dados de realidade. Assim, a proposta clínica foca-se em métodos qualitativos de interpretação, em que os próprios trabalhadores são chamados a refletir sobre suas práticas.

Segundo Lima (2011), as Clínicas do Trabalho propõem estudar os malestares do trabalho, que podem levar a várias consequências. Sua causa, no entanto, está no aumento do nível de exigência e demanda da organização sobre o indivíduo e na redução dos recursos pessoais e coletivos, o que conduz ao enfraquecimento do poder das ações dos indivíduos e ao afrouxamento dos laços do grupo (individuação).

Em relação a tais mal-estares, para Bendassolli e Soboll (2011a), quando o indivíduo fica enfraquecido do seu poder de ação sobre suas experiências com o meio ele 
estará susceptível a quatro diferentes grupos de patologias advindas do trabalho.

O primeiro grupo corresponde às "patologias da sobrecarga", cujos exemplos são: fadiga, burnout estresse e dissociações psicológicas. $\mathrm{O}$ bloqueio da atividade desempenhada pelo trabalhador é a principal característica, pois afeta a processo de subjetivação. $\mathrm{O}$ modo de organização taylorista impede o sujeito de exercer o controle sobre sua atividade, e é esse tipo de impedimento que afeta o trabalhador.

O segundo grupo é o das "patologias da solidão e da indeterminação no trabalho". Nesse caso, o coletivo é enfraquecido e o indivíduo fica fragilizado pela perda de laços. Alguns modelos de gestão de pessoas pautam suas ações nesse sentido, visando apartar o contato no trabalho para reverter esse tempo em produtividade. Tem-se, então, a questão da individuação sendo perseverada a partir de técnicas como desempenho individual, coaching e gestão de carreiras. Assim, adentra-se na questão da indeterminação no trabalho, já que esse trabalhador passa a ter dificuldades em refletir sobre os objetivos finais e os porquês de sua atividade.

Já o terceiro grupo está relacionado aos maus-tratos e à violência no ambiente de trabalho, por exemplos: assédio moral e exposição a situações de assimetria de poder.

O quarto grupo de patologias ligase às depressões, suicídios (ou tentativas de) e abalos mentais decorrentes de tais males.

Apesar do contraste epistemológico, teórico e metodológico das abordagens das Clínicas do Trabalho, outros quatro pontos, ainda, são comuns entre elas e devem ser ressaltados. $\mathrm{O}$ primeiro deles está relacionado ao interesse pela ação no trabalho, ou seja, o interesse que os sujeitos têm em poder agir nesse contexto, criando condições para que possam apropriar-se de sua atividade. $O$ segundo ponto está relacionado ao entendimento sobre $\mathrm{o}$ trabalho, o qual não está restrito às instituições, pois ele representa uma atividade de transformação da realidade e de construção de significados pessoais e sociais. O terceiro ponto é a defesa de uma teoria do sujeito, visto que o indivíduo não ocupa o lugar da máquina, mas representa um ser ativo dividido por conflitos intrapsíquicos e desejos, atravessado por forças histórico-sociais, condição que lhe permite desenvolver-se no confronto com o real. Por fim, o quarto ponto refere-se a um propósito, o do sofrimento no trabalho, no qual devemos considerar que o social pode causar ressonâncias na subjetividade e na vida psíquica do indivíduo (Bendassolli; Soboll, 2011a).

Há muitas outras questões envolvidas no trabalho do que apenas as que resvalam em seu caráter potencialmente psicopatológico. O próprio sofrimento que pode levar à patologia tem capacidade de mobilizar, no indivíduo, a criação e a superação das dificuldades postas pela realidade. Assim, essa clínica aparece, atualmente, em um cenário mais complexo de confrontação de teorias, oferecendo aos interessados uma rica controvérsia de estudos dentro da mesma proposta, sobrevivendo exatamente pelas discussões possibilitadas por essa posição.

\section{Últimas palavras}

Independentemente das teorias clínicas que adotarmos nesta pesquisa para referenciar as Clínicas do Trabalho, destacamos o diálogo estabelecido entre diferentes abordagens teóricas, visando ao desenvolvimento das compreensões do trabalho real. Contudo, ao fazê-lo, explicitamos de onde vêm os conceitos utilizados, já que cada abordagem se desenvolveu de maneira distinta, a partir de pressupostos teóricos diferentes. Tal postura confere esclarecimentos e possibilidades ao leitor para buscar mais informações sobre a diversidade que o texto traz.

Apesar de todas as clínicas dialogarem e terem na fala dos 
trabalhadores a base para atuações e análises, em relação à prática é inexequíve 1 utilizar dois métodos de abordagens distintas em uma mesma intervenção, haja vista as diferenças epistemológicas, teóricas e metodológicas de cada uma.

Por fim, aqueles profissionais que se dispuserem avançar na atuação do psicólogo do trabalho, encontrarão nas clínicas possibilidades de compreensão do trabalho real. Portanto, se uma teoria pretende estudar questões sobre o homem, o trabalho, a subjetividade e a saúde, ela deve, necessariamente, estar em contato direto com o contexto laboral, renovando-se o tempo todo. Todas as Clínicas do Trabalho estão buscando se desenvolver no diálogo e nos conflitos estabelecidos entre suas diferenças e aproximações teóricas.

Diversas dificuldades serão encontradas, não cabe enumerá-las aqui, quem está em contato com o campo já deve ter levantado várias delas em sua cabeça. Porém, compete ao psicólogo do trabalho conquistar, no cotidiano, esse novo campo para sua atuação. Cada caso, cada contrato, cada organização terá sua peculiaridade. Aqui está o desafio!

\section{Referências}

Amador, F.; Barros, M.E. B. e Fonseca, T.M.G. (2016). Clínicas do trabalho e paradigma estético. Porto Alegre: Editora UFRGS.

Bendassolli, P. F., Borges-Andrade, J. E. \& Malvezzi, S. (2010). Paradigmas, eixos temáticos e tensões na PTO no Brasil. In: Estudos de Psicologia, 15(3), setembro-dezembro, p. 281289.

Bendassolli, P. F. \& Soboll, L.A.P. (Orgs.). (2014). Métodos de pesquisa e intervenção em psicologia do trabalho: clínicas do trabalho. São Paulo: Atas.

Bendassolli, P. F. \& Soboll, L.A.P. (Orgs.). (2011a). Clínicas do trabalho: novas perspectivas para compreensão do trabalho na atualidade. São Paulo: Atas.

Bendassolli, P. F. \& Soboll, L.A.P. (2011b). Clínicas do trabalho: filiações, premissas e desafios. In: Cadernos de Psicologia Social do Trabalho, vol. 14, n.1, p. 59-72.

Dejours, C. (1992). A loucura no trabalho: estudo de psicopatologia do trabalho. (5.ed.). Trad. Ana Isabel Paraguay e Lúcia Leal Ferreira. São Paulo: Cortez; Oboré.

Enriquez, E. (2000). O indivíduo preso na armadilha da estrutura estratégica. In: Motta, F. C. P. \& Freitas, M. E. Vida psíquica e organização. Rio de Janeiro: Ed. FGV.

Gaulejac, V. (2001). Psicossociologia e sociologia clínica. In: Araújo, J. N. G. \& Carreteiro, T. C. (Orgs.). Cenários sociais e abordagem clínica. São Paulo: Escuta; Belo Horizonte: Fumec, p. 35-47.

Gondim, S. M. G., Borges-Andrade, J. E. \& Bastos, A. V. B. (2010). Psicologia do trabalho e das organizações: produção científica e desafios metodológicos. In: Psicologia em Pesquisa (UFRJ), vol. 4, n. 2, julh-dez, p. 84-99.

Le Guillant, L. (1984). Quelle psychiatrie pour notre temps. Toulouse: Érès.

Lhuillier, D. (2011a). Cliniques du travail. Toulouse: Éditions Érès.

Lhuillier, D. (2011b). Filiações teóricas das clínicas do trabalho. In: Bendassolli, P. F. \& Soboll, L. A. P. (Orgs.). Clínicas do trabalho: nova perspectiva para compreensão do trabalho na atualidade. São Paulo: Atlas, p. 22-58.

Lima, M. E. A. (2011). Abordagens clínicas e saúde mental no trabalho. In: Bendassolli, P. F. \& Soboll, L. A. P. (Orgs.). Clínicas do trabalho: nova perspectiva para compreensão do trabalho na atualidade. São Paulo: Atlas, p. 227-257.

Sévigny, R. (2001). Abordagens clínicas nas ciências humanas. In: Araújo, J. N. G. \& Carreteiro, T.C. (Orgs.). 
Cenários Sociais e abordagem clínica. São Paulo: Escuta, p. 35-47.

Sivadon, P. (1957). Psychiatrie du travail.

In H. Desaille (Org.). Cours de médicine $d u$ travail. Paris: Le François, p. 405-420.

Severino, A. J. (2007). Metodologia do Trabalho Científico. (23 ${ }^{\mathrm{a}}$ ed.). São Paulo: Cortez.

Thiollent, M. (2011). Metodologia da pesquisa-ação. São Paulo: Cortez.

Veil, C. (1964). Hygiène mentale du travail. Paris: Le François.

Zanelli, J. C., Borges-Andrade, J. E. \& Bastos, A. V. B. (Orgs.). (2007). Psicologia, organizações e trabalho no Brasil. Porto Alegre: Artmed.

Data de submissão: 16/08/2017

Data de aceite: 31/08/2017 